\title{
An Open-Label Pilot Study of Homeopathic Treatment of Attention Deficit Hyperactivity Disorder in Children and Youth
}

\author{
David Brulé ${ }^{a, b}$ Lauren Sule ${ }^{a}$ Beth Landau-Halpern ${ }^{b}$ Violeta Nastase ${ }^{b} \quad$ Umesh Jain $^{c}$ \\ Sunita Vohra ${ }^{d}$ Heather Boon ${ }^{\mathrm{a}}$ \\ a University of Toronto, ON, Canada \\ ${ }^{\mathrm{b}}$ Riverdale Homeopathic Clinic, Toronto, ON, Canada \\ ${ }^{\mathrm{c}}$ Centre for Addiction and Mental Health, Toronto, ON, Canada \\ ${ }^{d}$ University of Alberta, Edmonton, AB, Canada
}

\section{Keywords}

Attention deficit hyperactivity disorder . Homeopathy Complementary and alternative medicine ADHD pediatrics . Mental health

\section{Summary}

Background: An open-label pilot study of individualized homeopathy for attention deficit hyperactivity disorder (ADHD) was conducted to assess the potential for future studies with a focus on the feasibility of the recruitment plan and outcome measure schedules; identification of any group characteristics of participants who respond significantly to the therapy; and establishing the length of time required for an improvement in ADHD symptoms. Patients and Methods: Participants (aged 6-16) were recruited through community advertisement and outreach. Participants completed 1 screening and 9 individualized homeopathic follow-up consultations. ADHD symptoms were assessed using the Conners 3 - Parent Questionnaire administered at each consultation. The pre- and post-study difference in Conners Global Index - Parent (CGI-P) Tscore was evaluated for each participant. Baseline data of those who showed a statistically significant improvement (responders) were compared to those who did not (non-responders). Results: 35 participants were enrolled over 11 months. $80 \%$ completed all 10 consultations in a median of 12.1 months. $63 \%$ had a statistically significant improvement in the primary outcome, first occurring after a mean of 4.5 visits. Overall scores for participants completing at least 2 data points decreased from a baseline median of 85.5 to 74.0 ( $p<0.001, \mathrm{Cl} 95 \%$ ). There were no significant baseline differences between responders and non-responders. No serious adverse events related to the therapy were reported. Conclusion: The change in the median CGI-P T-score from baseline to the end of this open-label pilot study was statistically significant. The research methods are feasible. Future studies are warranted. Trial registration: NCT01141634.

\author{
Schlüsselwörter \\ Aufmerksamkeitsdefizit-/Hyperaktivitätsstörung · Homöopathie · \\ Komplementäre und alternative Medizin . ADHS in der Pädiatrie . \\ Geistige Gesundheit
}

\section{Zusammenfassung}

Hintergrund: Wir führten eine Open-Label-Pilotstudie zur individualisierten Hoomöopathiebehandlung der Aufmerksamkeitsdefizit-/ Hyperaktivitätsstörung durch. Ziel der Untersuchung war es, das Potenzial für künftige Studien zu erfassen, indem wir die Durchführbarkeit eines Rekrutierungs- und Erhebungsplans sowie die Möglichkeiten der Identifizierung von Gruppencharakteristika der Teilnehmer prüften, die signifikant auf die Behandlung ansprechen, und die Dauer für eine erfolgreiche Behandlung von ADHS-Symptomen bestimmten. Patienten und Methoden: Die Teilnehmer (zwischen 6 und 16 Jahre alt) wurden durch Werbung und Kontakte rekrutiert. Die Probanden unterzogen sich einer Voruntersuchung und 9 individualisierten homöopathischen Nachfolgeuntersuchungen. Die ADHS-Symptome wurden mittels "Conners 3 - Parent Questionnaire" bei jeder Visite erfasst. Unterschiede, die sich aus der Vor- und Nachstudienphase ergaben (Conners Global Index - Parent (CGI-P) T-score), wurde für jeden Teilnehmer erhoben. Die Baselinedaten der Teilnehmer, bei denen sich eine statistisch signifikante Verbesserung der Symptome einstellte (Responder), wurden mit denen der Teilnehmer verglichen, bei denen keine Symptomreduktion festgestellt werden konnte (Non-Responder). Ergebnisse: 35 Teilnehmer wurden über 11 Monate in die Studie eingeschlossen. $80 \%$ von ihnen nahmen an allen $10 \mathrm{Be}-$ handlungen teil (Median 12,1 Monate). Bei 63\% konnte eine statistisch signifikante Verbesserung des primären Outcomes festgestellt werden, die im Mittel erstmals nach 4,5 Visiten erfolgte. Die Ergebnisse der Teilnehmer, die mindestens 2 Datenpunkte erreicht haben, sanken von einem Baselinemedian von 85,5 auf 74,0 ( $p<0,001, \mathrm{Cl}$ $95 \%$ ). Es wurden keine signifikanten Baselineunterschiede zwischen den Respondern und Nicht-Respondern festgestellt. Schwerwiegende unerwünschte Nebenwirkungen wurden nicht berichtet. Schlussfolgerung: Ausgehend von der Baseline bis zum Abschluss der Studie waren die Veränderungen im Median des CGI-P T-Scores statistisch signifikant. Die Untersuchungsmethoden sind anwendungsfähig. Weitere Studien in diesem Feld sind geboten. Studienregistrierung: NCT01141634.

\section{KARGER \\ Fax +497614520714 \\ Information@Karger.com}

www.karger.com
(C) 2014 S. Karger GmbH, Freiburg

1661-4119/14/0215-0302\$39.50/0

Accessible online at:

www.karger.com/fok
David Brulé, BA, DHMS (Can.)

1331 Danforth Avenue

Toronto, ON, Canada M4J 1N1

david.brule@utoronto.ca 


\section{Background}

Attention deficit hyperactivity disorder (ADHD) is the most prevalent mental disorder in children worldwide, with boys more likely to be affected than girls [1]. Most recent Canadian data suggest that almost $3 \%$ of Canadian children are diagnosed with ADHD [2]. Children with ADHD suffer from a wide range of symptoms including inattention, impulsivity, and an inability to concentrate. While many children find effective treatment through either stimulant medications or behavioral interventions, approximately $30 \%$ of diagnosed children are not well-served by these treatment options [3]. Two-thirds of those with ADHD have been reported to be using complementary and alternative medicine (CAM) treatments of some kind [4]. This study examines homeopathic treatment as a possible therapy for children with ADHD.

Homeopathy involves treatment of patients with diluted natural substances aimed at stimulating the body's healing system [5]. Homeopathy is controversial primarily because there are no accepted explanations for its mechanism of action [6,7]. In general, results of systematic reviews of trials in homeopathy have yielded conflicting results, with some meta-analyses reporting that homeopathic treatments for a variety of conditions are associated with positive results compared to placebo, while others demonstrating no difference compared with placebo / no treatment $[8,9]$.

Current research best practices highlight strategies to balance internal, model, and external validity. Recommended study design features in this field include allowing choice and change of the homeopathic remedy intervention throughout the course of the treatment period; performing pilot analyses to obtain accurate estimates of effect size achievable by specific practitioners; and testing long treatment periods to enable observation of remedy changes over the course of treatment [10-14].

A systematic review of trials investigating homeopathic treatment for ADHD published in the Cochrane database was inconclusive, likely due to the heterogeneity of the trials included in the analysis [13]. Of the 4 studies that were considered rigorous enough for further analysis in this review, 3 investigated individualized treatments and 1 [15] investigated the effects of a fixed combination homeopathic remedy to treat all participants diagnosed with ADHD. The latter showed the least positive results of any of the studies to date, suggesting further research that focuses on individualized homeopathic treatment for ADHD.

The study by Frei et al. [16] highlighted the importance of allowing the clinical team to change medication prescriptions, and designing a study that is long enough to capture the effects of homeopathic treatment. During the open-label run-in phase, the mean time required for his clinical team to find the correct remedy was 5.1 months. This mean time was longer than the entire treatment phase in other studies, suggesting that the other studies may not have had long enough treat- ment phases to adequately investigate the effects. In a followup paper, Frei et al. emphasized that future research would benefit from studies that offer an extended treatment phase and freedom of remedy choice and/or change by classical homeopaths (i.e. those prescribing individualized homeopathic treatment) [12].

\section{Objectives}

The objectives of this open-label pilot study were to:

1. Assess the feasibility of the recruitment plan and outcome measure schedules, and to determine whether a followup randomized controlled trial was warranted based on assessment of the following pre-defined criteria: feasibility of enrollment rate of 15 participants per year; dropout rate less than $25 \%$; absence of serious adverse events (AE) likely related to therapy; a statistically significant group treatment effect in the primary outcome measure.

2. Identify any group characteristics of participants who respond significantly to the therapy.

3. Establish the length of time required for an improvement in ADHD symptoms, in the individual and in the group, as measured by a statistically significant change in the Conners Global Index - Parent (CGI-P) T-score.

\section{Methods}

This was an open-label pilot study of individualized homeopathic treatment of ADHD.

\section{Setting and Participants}

Participants from the community were recruited from June 2010 to November 2011 using a variety of methods (word of mouth, posters, seminars, ADHD advocacy group contact, referrals from a mental health hospital). Potential participants underwent a confirmatory diagnostic interview with the study psychiatrist, and those meeting the inclusion/exclusion criteria were invited to participate in the study. Participants were aged 6-16 years with a diagnosis of ADHD. Participants could not have an additional mental health disorder including, but not limited to, Autism Spectrum Disorder, Bipolar Disorder, Conduct Disorder, or Major Depressive Disorder. Ethical approval was obtained through the Centre for Addiction and Mental Health Research Ethics Board (CAMH REB 158/2009). Parents/guardians of the participants provided written informed consent; child participants provided initial and ongoing assent. Participants were forewarned of the potential for homeopathic aggravations resulting from treatment.

\section{Sample Size}

We based our sample size on Conners 3 - Parent content scales and their relation to the Reliable Change Index which, according to the developers of the scale, corresponds to a statistically significant change $90 \%$ of the time [17]. Combining this with the previous experience of the team and dropout rates of previous, similar studies, it was estimated that 36 participants would provide adequate data to assess the feasibility of designing a larger study. 


\section{Study Procedures}

Consenting parents/guardians and child participants attended the baseline (in clinic) visit. The 9 follow-up homeopathic consultations with the parent/guardian were either in clinic, via telephone or teleconference (skype) with child participant attendance optional. Time between visits was approximately 1 month. 2 homeopaths ( 1 with dual training in western and homeopathic medicine) trained in individualized homeopathic methods (each with over 10 years of experience, practicing more than 25 clinic h per week) conducted a homeopathic interview and prescribed a homeopathic treatment consistent with standard practice at each consultation. Outcome measure tools were completed prior to all consultations. There were no consultation or medicine fees for the participants.

Prior to every consultation, the study coordinator recorded concomitant medications, any other treatments, and AE. AE were recorded in compliance with the International Conference on Harmonisation of Technical Requirements for Registration of Pharmaceuticals for Human Use guidelines for the expedited reporting of AE [18]. Reported AE were assessed by the study coordinator based on the Common Terminology Criteria for Adverse Events Version 4 [19] to determine if there was a 'possible', 'probable', or 'definite' relationship to therapy, and these were grouped into categories to estimate the frequency of their occurrence. Any AE suspected of being serious were forwarded to the independent Data Safety and Monitoring Board for assessment.

\section{Interventions}

\section{The Homeopathic Consultation}

The homeopathic consultations occurred at a private homeopathic clinic in Toronto, Canada. The method of case taking was classical and the case analysis was performed using repertory software [20] and/or Synthesis 9.1 repertory [21] as well as various materia medica [22-25]. The consultation emulated normal practice and varied in length (baseline approximately $1.5 \mathrm{~h}$, follow-up 30-45 $\mathrm{min}$ ) and content according to the individual. The homeopaths practiced usual homeopathic care based on the principles of Hahnemann's Organon of Medicine [5]; this care model includes advice to remove potential causative factors, such as trigger foods and substances.

\section{Trial Medication}

Trial medications were either given directly or sent by mail to the parent/guardian. The 2 acceptable formats of the intervention were: a) 2.5 $\mathrm{mm}$ spherical lactose/sucrose granule embedded with homeopathic medicine taken sublingually; or b) 3-4 $2.5 \mathrm{~mm}$ spherical lactose/sucrose granules embedded with homeopathic medicine dissolved in $250 \mathrm{ml}$ spring water and succussed (2 'bangs' into the palm of the hand), taken orally (held in the mouth for $10 \mathrm{~s}$ before swallowing). Dosage regimens were at the discretion of the homeopath and ranged from one single dose between consultations to once daily dosing between consultations. Homeopathic remedy potencies were in the centesimal scale and were chosen at the discretion of the homeopath within the range of $6 \mathrm{CH}$ and $1 \mathrm{M}$. The homeopaths chose remedies from those available through Boiron Canada Inc. (Saint-Bruno, QC, Canada) and which carried a DIN-HM (a designation provided by Health Canada allowing for over-the-counter use). Remedies manufactured by Boiron Canada are prepared using the Hahnemannian multi-vial method and prepared according to the European Pharmacopoeia, the Pharmacopée Française, and the Homeopathic Pharmacopeia of the USA. All participants were asked to take the homeopathic medicine $0.5 \mathrm{~h}$ prior to food and/or beverage intake, or exposure to strong smelling substances.

\section{Outcome Measures and Analysis}

To assess the feasibility of the recruitment strategies, we calculated the total time for enrolling the sample of 36 participants, seasonal variation in enrollment, dropout rate, and average time required to complete the study (10 consultations). To assess the feasibility of the outcome measures, the number of completed questionnaires was determined.

The primary clinical outcome we assessed for feasibility was change in ADHD symptoms from baseline to study completion, as measured by the CGI-P T-score from the Conners 3 - Parent assessment tool (Conners 3-P) [17]. The Conners 3-P is a 108-item questionnaire which assesses behaviors and other concerns in children aged 6-18. The Conners 3-P has been shown to have factorial validity, construct validity (including relationships with other related measures), and predictive validity (including the ability of the Conners 3-P to differentiate between youth with ADHD and those without a clinical diagnosis) [17].

Participants in the study were classified as 'responders' or 'non-responders' based on whether they achieved a statistically significant difference between their initial and final CGI-P T-scores according to the Conners Reliable Change Index. For participants classified as responders, the number of visits needed to achieve a statistically significant change in CGI-P T-score was established by computing the T-score difference from baseline to each subsequent visit and then comparing these differences to the Conners Reliable Change Index value to determine statistical significance.

For participants who did not complete 10 consultations, the last recorded CGI-P T-score was carried forward as the final score. This method was also used in the secondary analyses of the Conners 3-P subscale scores. The validity of Conners 3-P responses was explored through a response style analysis, in order to detect possible positive, negative, or inconsistent response styles using the scores for the Conners Positive and Negative Impression validity scales and the Inconsistency Index. Secondary outcomes included the change from baseline to study completion in the Conners ADHD Index Probability score, Conners Content Scale Tscores for Inattention and Hyperactivity/Impulsivity, and Conners DSMIV-TR Symptom Scale T-scores for the ADHD Inattentive and ADHD Hyperactive-Impulsive subtypes.

The study clinicians rated their confidence that the homeopathic prescription was 'right' (i.e. was going to have a positive impact on the patient's symptoms) for each prescription on a 10-point scale designed by the authors for this study.

Changes in therapies for ADHD, including both prescription medication use and over-the-counter products, dietary changes, and any other types of therapy were monitored throughout the study.

\section{Results}

\section{Study Participants}

There were 72 inquires about the study, and 41 people agreed to do the psychiatric assessment (fig. 1).

\section{Primary Outcomes}

\section{Feasibility - Recruitment}

Thirty-six participants began the study. 6 girls and 30 boys at mean age of 10.2 (age range 6-16) were enrolled over a period of 11 months (table 1). It was observed that recruitment rates varied seasonally based on the school year calendar; recruitment was low from May to September. 
Table 1. Participant characteristics

\begin{tabular}{|c|c|c|c|c|}
\hline & $\mathrm{N}=35$ & Responders, $\mathrm{n}=22$ & Non-responders, $\mathrm{n}=13$ & p-value \\
\hline Mean age at study intake & $10.2\left(2.49^{*}\right)$ & $10.3\left(2.53^{*}\right)$ & $10.08\left(2.53^{*}\right)$ & $0.775^{\mathrm{a}}$ \\
\hline Gender & 29 males, 6 females & 17 males, 5 females & 12 males, 1 female & $0.377^{\mathrm{b}}$ \\
\hline Months in study, mean & $11.06\left(3.26^{*}\right)$ & $11.39\left(3.21^{*}\right)$ & $10.52\left(3.40^{*}\right)$ & $0.335^{\mathrm{a}}$ \\
\hline Initial weight, mean $\mathrm{kg}$ & $35.7\left(12.59^{\prime \prime}\right)$ & $36.5\left(12.48^{*}\right)$ & $34.6\left(13.61^{*}\right)$ & $0.727^{\mathrm{a}}$ \\
\hline Last recorded weight, mean $\mathrm{kg}$ & $37.5\left(13.32^{*}\right)$ & $38.6\left(13.79^{*}\right)$ & $36.3\left(13.38^{*}\right)$ & $0.649^{\mathrm{a}}$ \\
\hline \multicolumn{4}{|l|}{ Annual household income, $\%$} & \multirow[t]{2}{*}{$0.649^{\mathrm{a}}$} \\
\hline >USD 65,000 & 60 & 64 & 54 & \\
\hline \multicolumn{4}{|l|}{ Highest level of parent education, \% } & \multirow[t]{2}{*}{$0.724^{\mathrm{a}}$} \\
\hline Undergraduate or graduate degree & 63 & 64 & 62 & \\
\hline $\begin{array}{l}\text { Prescription medications for ADHD at baseline, } \\
\text { mean } \mathrm{n}\end{array}$ & $0.6\left(0.77^{*}\right)$ & $0.6\left(0.8^{*}\right)$ & $0.6\left(0.77^{*}\right)$ & $0.749^{\mathrm{a}}$ \\
\hline $\begin{array}{l}\text { Intake of any prescription medications for ADHD at } \\
\text { baseline, } \%\end{array}$ & 43 & 41 & 46 & $0.801^{\mathrm{a}}$ \\
\hline Therapies for ADHD at baseline, mean $\mathrm{n}$ & $1.2\left(1.44^{*}\right)$ & $1.18\left(1.68^{*}\right)$ & $1.23\left(1.01^{*}\right)$ & $0.408^{\mathrm{a}}$ \\
\hline Any therapies for ADHD at baseline, $\%$ & 71 & 73 & 69 & $0.880^{\mathrm{a}}$ \\
\hline Initial CGI-P T-score, mean & $82.1\left(9.03^{*}\right)$ & $82.7\left(9.26^{*}\right)$ & $81.2\left(8.91^{*}\right)$ & $0.625^{\mathrm{a}}$ \\
\hline Remedies Prescribed, mean n & $3.1\left(1.71^{*}\right)$ & $3.0\left(1.72^{*}\right)$ & $3.2\left(1.77^{*}\right)$ & $0.880^{\mathrm{a}}$ \\
\hline Dietary changes, $\%$ & 17 & 18 & 15 & $0.838^{\mathrm{a}}$ \\
\hline Compliance, mean, \% & $92.1\left(21.29^{*}\right)$ & $94.1\left(18.37^{*}\right)$ & $89.28\left(23.90^{*}\right)$ & $0.053^{\mathrm{a}}$ \\
\hline $\begin{array}{l}\text { Overall clinician confidence in the accuracy of remedies } \\
\text { prescribed, mean }\end{array}$ & $8.6\left(1.22^{*}\right)$ & $8.8\left(1.16^{*}\right)$ & $8.2\left(1.26^{*}\right)$ & $0.003^{\mathrm{a}^{*}}$ \\
\hline 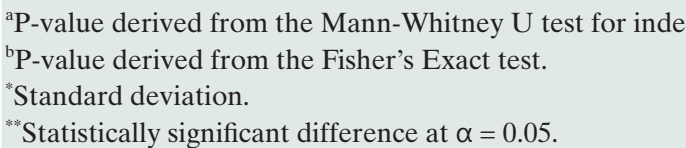 & ndent groups. & & & \\
\hline
\end{tabular}

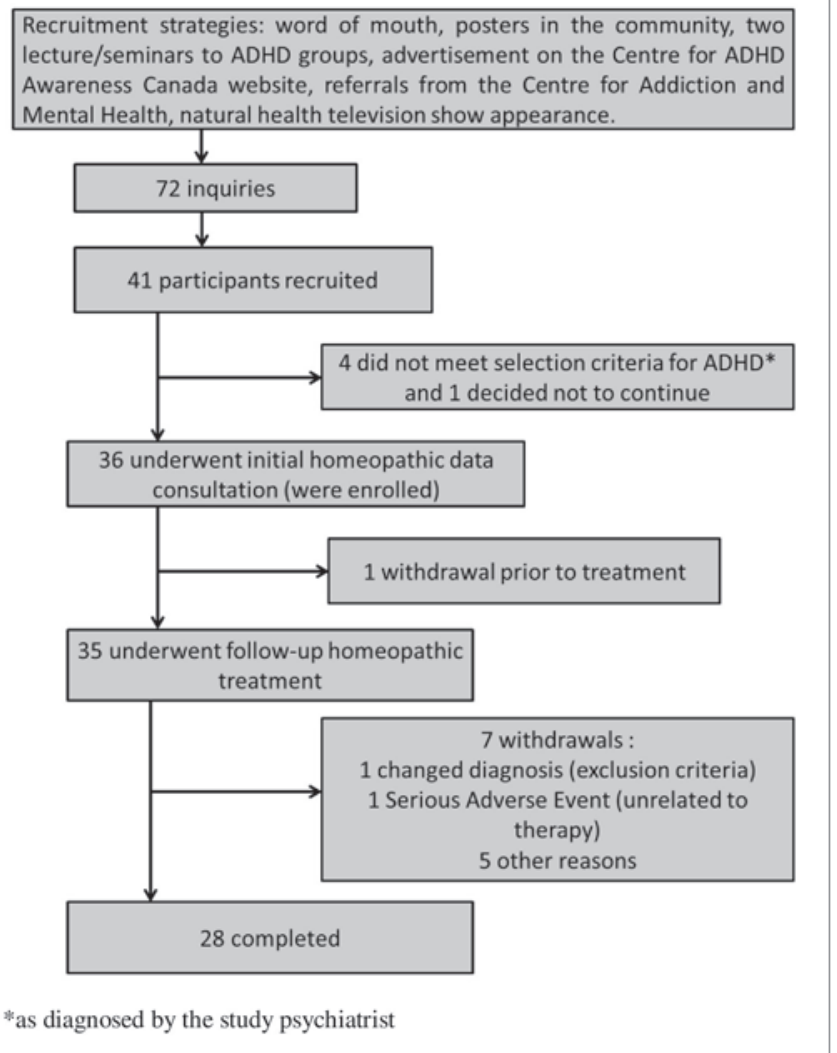

Fig. 1. Flow chart of study participants' recruitment.
Seventy-eight percent (28/36) of participants completed the study (10 consultations) in a median of 12.1 months (range 0.00-16.75 months). 1 participant dropped out prior to treatment (and is not included in the analysis of AE, group characteristics, and treatment effects); 2 participants dropped out of the study after completing 3 visits, 3 participants after 6 visits, and 2 participants after 7 visits.

Participants who withdrew from the study did not differ significantly in any of the categories listed above (data not shown).

\section{Feasibility - Compliance}

Overall, $82 \%$ of Conners 3-P questionnaires, $86 \%$ of Clinical Global Impression scales, and $45 \%$ of Clinician Confidence forms were completed.

\section{Feasibility - Adverse Events}

In total, 23/35 (65.7\%) participants reported having an $\mathrm{AE}$ related to therapy. All AE reported were of mild to moderate severity and were transient or self-limiting with no long-term effects. In many participants, exacerbations of symptoms or behavior related to ADHD occurred (table 2). The Data Safety and Monitoring Board reviewed 2 AE suspected of being serious - 1 was deemed not serious and is included in table 1; the other was classified as a serious AE because the participant was hospitalized after being struck by a truck while riding 
Table 2. Reported adverse events assessed to have a possible, probable, or definite relationship to therapy

\begin{tabular}{llll}
\hline Mild severity & Total reports & Moderate severity & Total reports \\
\hline Oppositional behavior, defiance, argumentativeness & 6 & shaking legs and hands & 1 \\
Anger, loss of temper, tantrums & 6 & stomach upset \\
Sleep problems (sleep difficulties, night terrors) & 6 & self-inflicted injury \\
Violence, aggression, bullying & 5 & violent episode & blood/red spots on face, \\
Hyperactivity & 4 & chest and arms \\
Disruptive behavior & 3 & \\
Increase in symptoms & 2 & \\
Other mental / emotional signs or symptoms $\quad 10$ & \\
$\quad$ (clinginess/sensitivity, emotional volatility, & & \\
$\quad$ moulsivity, inattentiveness, irritability, & & \\
Other physical issues (appetite decrease, eye problems, & 7 & \\
$\quad$ headaches, nosebleed, nose/throat discomfort) & & \\
\hline
\end{tabular}

Table 3. Differences in Conners subscale scores from baseline to final assessment

\begin{tabular}{|c|c|c|c|c|}
\hline Outcome scale & $\begin{array}{l}\text { Baseline group } \\
\text { median }\end{array}$ & $\begin{array}{l}\text { Final group } \\
\text { median }\end{array}$ & p-value ${ }^{*}$ & $\begin{array}{l}\text { Individuals with statistically } \\
\text { significant change, } \%\end{array}$ \\
\hline Conners Global Index T-score & 85.5 & 74.0 & $<0.001$ & 63 \\
\hline Conners ADHD Index Probability score & 99.0 & 91.0 & $<0.001$ & $\mathrm{~N} / \mathrm{A}^{* *}$ \\
\hline Conners Content scale T-score for Inattention & 85.0 & 75.0 & $<0.001$ & 34 \\
\hline $\begin{array}{l}\text { Conners Content scale T-score for Hyperactivity/ } \\
\text { Impulsivity }\end{array}$ & 84.0 & 78.0 & $<0.001$ & 51 \\
\hline $\begin{array}{l}\text { Conners DSM-IV-TR Symptom scale T-score for } \\
\text { the ADHD Inattentive subtype }\end{array}$ & 84.0 & 72.5 & $<0.001$ & 34 \\
\hline $\begin{array}{l}\text { Conners DSM-IV-TR Symptom scale T-score for } \\
\text { the ADHD Hyperactive-Impulsive subtype }\end{array}$ & 81.5 & 74.0 & $<0.001$ & 51 \\
\hline
\end{tabular}

a bicycle. After consideration of the details of the event, including the length of time between dose and AE, this AE was deemed not likely to be related to the study therapy.

\section{Feasibility: Estimates of Treatment Effects}

A statistically significant improvement from baseline to study completion was observed for the primary outcome and for each of the secondary outcomes examined (table 3 ).

\section{Responder/Non-Responder Group Characteristics}

Sixty-three percent (22/35) of participants achieved a statistically significant improvement in their CGI-P T-score from baseline to the end of the study and thus were defined as responders.

There were neither significant baseline differences between responders and non-responders (table 1) nor any significant differences in the number of homeopathic remedies prescribed or compliance to study therapies, which was high in all participants.

\section{Secondary Outcome Measures}

\section{Clinician Comparison and Confidence}

For all participants, the average clinician confidence in the accuracy of the remedy prescribed immediately prior to the first visit, at which a statistically significant change in CGI-P T-score occurred, was 8.4/10. The clinician confidence ratings of the accuracy of homeopathic remedies prescribed were found to be significantly higher for responders than non-responders (table 1).

For participants having completed the study (10 consultations), the homeopathic clinicians decided upon a final remedy after a mean of 4.5 visits (range 2-10). For responders, they prescribed on average 1.7 different remedies (standard deviation $(S D)=1.03)$ prior to the initial, significant improvement.

There were no significant differences in the participants' Conners Global Index T-scores between the 2 homeopaths ( $\mathrm{p}=0.858$, CI 95\%). 


\section{Changes in Prescription Medication Use}

Changes in the use of prescription medications for ADHD (stimulants and non-stimulants, such as anti-depressants) were monitored throughout the study. 2 participants (both classified as study responders) reported a decrease in prescription medication use during the study. 6 participants (3 responders; 3 non-responders) reported an increase in prescription medication use. 1 participant (responder) started stimulant medication during the course of the study. Removing participants from the analysis who were identified as having inconsistent response styles to the Conners 3-P, and/or those who reported an increase in prescription medication use during the trial did not change the significance in the primary and secondary outcome measures (all p-values $<0.001$ ).

\section{Timeline of Response}

For participants classified as responders, a statistically significant improvement in CGI-P T-score first occurred after a mean of 4.5 visits $(S D=2.67)$ and 4.6 months $(S D=4.03)$.

\section{Homeopathic Medicines Used}

Below are the homeopathic medicines used and the frequency as well as the number of times the remedy was chosen prior to significant improvement (in brackets). All medicines were used individually.

Phosphorus (9/2), Hyoscyamus niger (8/1), Tuberculinum (6/4), Tarentula hispanica (5/0), Lycopodium clavatum (4/3), Anacardium orientale (4/1), Lachesis muta (4/1), Stramonium (4/1), Veratrum album (4/0), Lac caninum (3/1), Nux vomica (3/1), Pulsatilla (3/1), Belladonna (3/0), Saccharum officinalis (2/1), Calcarea phophorica (2/0), Aconitum (2/0), Aranea ixabola (2/0), Gallicum acidum (2/0), Natrum muriaticum (2/0), Agnus castus (1/0), Agaricus muscarius (1/0), Apis mellifica (1/0), Baryta carbonica (1/0), Bryonia alba (1/0), Bufo rana (1/0), Calcarea carbonica (1/1), Cuprum metallicum (1/1), Ferrum phosphoricum (1/0), Hepar sulphuris calcareum (1/0), Kalium phosphoricum (1/1), Luesinum (1/0), Magnesium carbonica (1/0), Medorrhinum $(1 / 1)$, Natrum silicata (1/0), Silicea (1/1), Staphysagria (1/0), Sulphur $(1 / 0)$, Thuja occidentalis $(1 / 0)$, Veratrum viride $(1 / 0)$.

Individual dosage regimens for all participants are available from the authors.

\section{Discussion}

The purpose of this study was to evaluate whether future, more rigorous study is warranted and feasible, and if so, to provide a preliminary estimate of treatment effect.

\section{Feasibility}

The research methods used in this study including recruitment and outcome assessment were feasible. Recruitment strategies were effective, as sufficient interest was generated in the study to exceed the target enrollment rate. The dropout rate was lower than the pre-defined maximum of $25 \%$, and although there was $1 \mathrm{AE}$ of serious severity, the study safety committee deemed it not likely to be related to study therapy. One limitation is that this study is unable to assess the feasibility of a randomized and/or blinded study design; although previous blinded studies of homeopathic ADHD treatment have not had difficulty reaching their recruitment targets $[16,26]$, additional pilot work may be needed to determine if such a study design will impact recruitment.

\section{Treatment Effects}

Sixty-three percent of participants in this study reported a statistically significant improvement in their ADHD symptoms. Since this was an open-label design, any improvement in symptom scores can be attributed to a variety of effects including, but not limited to, consultation effects, remedy effects, placebo effects, natural course of the disease, and effects of participating in a trial. Any positive result must therefore be interpreted with caution as evidence of a possible effect of homeopathic treatment for ADHD in a real-world setting, but not as proof of any specific effect. The results of participants who were taking conventional treatments are encouraging - homeopathic treatment was an effective adjunctive treatment for 8 of the 15 participants who were taking stimulant medication at baseline. This study suggests that further research to determine whether there is a specific effect of homeopathic treatment in general and of homeopathic remedies in particular is warranted.

Changes in the use of prescription medications for ADHD were monitored throughout the study. 2 participants reported a decrease in prescription medication use and were classified as responders, suggesting that their improvement was likely not solely due to treatment with conventional therapies. The primary outcome analysis retained statistical significance after removing participants classified as responders who had reported an increase in medication use, suggesting that the magnitude of improvement due potentially to conventional medications was not significant. Similarly, there were no significant differences in responders versus non-responders with regards to any dietary changes undertaken by the participants.

\section{Adverse Events}

AE data were sought in an open-ended fashion (by a direct questioning from the study coordinator posed at the beginning of each consultation), and did not differentiate between unexpected AE versus those that were clinically expected (also known as homeopathic remedy aggravations - described in the homeopathic literature as a mild and self-limiting increase in symptoms at the beginning of treatment) [5]. Participants were also forewarned of the potential for homeopathic aggravations resulting from treatment. Many of the AE reported appeared to be symptoms of ADHD (e.g., inattention, hyperactivity) but also may have been homeopathic remedy aggravations. Future studies should attempt to differentiate homeopathic remedy aggravations from unexpected AE. 


\section{Clinical Implications}

The treatment of ADHD is fraught with difficult decisions for parents and health care professionals alike. Conventional medications are often very effective: effect sizes in studies of stimulant medications using the same primary outcome measure are in the range of a $50 \%$ reduction in symptoms after 1 week [27], whereas our study found a $25 \%$ reduction in symptoms after an average of 12.1 months.

Unfortunately, there are a host of direct and indirect AE associated with the use and abuse of stimulant medications [28]. Although less dramatically effective, this study suggests that more research is warranted to explore whether homeopathic treatment may be a safer treatment for ADHD that can be used either as a stand-alone treatment or as an adjunctive therapy to conventional medications.

\section{Conclusions}

This study demonstrated that the methods used were feasible and that a future, randomized controlled study designed to assess the effects of homeopathic treatment and medication in the management of ADHD is warranted. Future study should also capture clinically relevant AE data.

\section{Disclosure Statement}

This trial was funded through a grant from the SickKids Foundation. L.S. was funded through the University of Toronto summer undergraduate research program at the Leslie Dan Faculty of Pharmacy. S.V. receives salary support as an Alberta Innovates-Health Solutions Health Scholar. D.B. is owner of a commercial homeopathic clinic and retail supplies outlet (Riverdale Homeopathy, 1749863 Ontario Ltd.). All other authors declare that they have no competing interests.

\section{Authors' Contributions}

D.B. and H.B. contributed to the design of the study; acquisition, analysis and interpretation of data; and preparation of the manuscript. B.L.H. and V.N. were involved in the acquisition of data and contributed to interpretation of data and preparation of the manuscript. L.S. contributed to data analysis. U.J. and S.V. contributed to the design of the study and the preparation of the manuscript. All authors read and approved the final manuscript.

\section{Acknowledgements}

We thank Anna Taddio, Dugald Seely, and Soloman Shapiro for their participation in the Data and Safety Monitoring Board. We thank the study participants and their parents/ guardians for their participation.

\section{References}

1 Polanczyk G, de Lima M, Horta B, Biederman J, Rohde LA: The worldwide prevalence of ADHD: a systematic review and metaregression analysis. Am J Psychiatry 2007;164:943.

2 Brault M-C, Lacourse E: Prevalence of prescribed attention-deficit hyperactivity disorder medications and diagnosis among Canadian pre-schoolers and school-age children 1994-2007. Can J Psychiatry 2012:57:93-101.

3 Biederman J, Spencer T, Wilens T: Evidence-based pharmacotherapy for attention-deficit hyperactivity disorder. Int J Neuropsychopharmacol 2004;7:77-97.

4 Sinha D, Efron D: Complementary and alternative medicine use in children with attention deficit hyperactivity disorder. J Paediatr Child Health 2005; 41:23-26.

5 Hahnemann S: Organon of the Medical Art, ed 6. Palo Alto, Birdcage Press, 1996.

6 Vandenbroucke JP: Homoeopathy trials: going nowhere. Lancet 1997;350:824.

7 Walach H, Jonas WB, Ives J, van Wijk R, Weingärtner O: Research on homeopathy: state of the art. J Altern Complement Med 2005;11:813-829.

$\checkmark 8$ Linde K, Clausius N, Ramirez G, Melchart D, Eitel F, Hedges LV, Jonas WB: Are the clinical effects of homeopathy placebo effects? A meta-analysis of placebo-controlled trials. Lancet 1997;350:834-843.

9 Shang A, Huwiler-Muntener K, Nartey L, Juni P, Dorig S, Sterne JA, Pewsner D, Egger M: Are the clinical effects of homoeopathy placebo effects? Comparative study of placebo-controlled trials of homoeopathy and allopathy. Lancet 2005;366:726-732.
10 Bell I: Depression research in homeopathy: hopeless or hopeful? Homeopathy 2005;94:141-144.

11 Bornhöft G, Maxion-Bergemann S, Wolf U, Kienle GS, Michalsen A, Vollmar HC, Gilbertson S, Matthiessen PF: Checklist for the qualitative evaluation of clinical studies with particular focus on external validity and model validity. BMC Med Res Methodol 2006;6:56

12 Frei H, Everts R, von Ammon K, Kaufmann F, Walther D, Schmitz SF, Collenberg M, Steinlin M, Lim C, Thurneysen A: Randomised controlled trials of homeopathy in hyperactive children: treatment procedure leads to an unconventional study design. Experience with open-label homeopathic treatment preceding the Swiss ADHD placebo controlled, randomised, double-blind, cross-over trial. Homeopathy 2007;96:35-41.

13 Heirs MK, Dean ME: Homeopathy for attention deficit/hyperactivity disorder or hyperkinetic disorder. Cochrane Database Syst Rev 2007;CD005648.

14 Mathie RT, Roniger H, Van Wassenhoven M, Frye J, Jacobs J, Oberbaum M, Bordet M-F, Nayak C, Chaufferin G, Ives JA, Dantas F, Fisher P: Method for appraising model validity of randomized controlled trials of homeopathic treatment: multi-rater concordance study. BMC Med Res Methodol 2012;12:49.

15 Strauss LC: The efficacy of a homeopathic preparation in the management of Attention Deficit Hyperactivity Disorder. Biomedical Therapy 2000;18: 197-201.
16 Frei H, Everts R, Von Ammon K, Kaufmann F, Walther D, Hsu-Schmitz SF, Collenberg M, Fuhrer K, Hassink R, Steinlin M, Thurneysen A: Homeopathic treatment of children with attention deficit hyperactivity disorder: a randomised, double blind placebo-controlled crossover trial. Eur J Ped 2005; 164:758-767.

17 Conners CK: Conners Rating Scales (Revised), Technical Manual. Toronto, Multi-Health Systems, 2008.

18 International Conference on Harmonisation of Technical Requirements for Registration of Pharmaceuticals for Human Use (ICH) guideline. www.ich.org (accessed 04.09.2014).

19 Common Terminology Criteria for Adverse Events (CTCAE), version 4.0, U.S. Department of Health and Human Services, National Institutes of Health. http://evs.nci.nih.gov/ftp1/CTCAE/CTCAE_4.03 2010-06-14_QuickReference_5x7.pdf (accessed 04.09.2014).

20 RADAR Homeopathic software. www.archibel.com/radar.html (accessed 04.09.2014).

21 Schroyens F: Synthesis Repertorium Homeopathicum 9.1. London, Homeopathic Book Publishers, 2004.

22 Master F: Clinical Observations of Children's Remedies. Eindhoven, Lutra Services, 2003.

23 Murphy R: Nature's Materia Medica. Blacksburg, Lotus Health Institute, 2006.

24 Petrucci R: Children - Homeopathic Materia Medica with Repertorial Symptoms. Isnes, Archibel Publications, 2007. 
25 Vermeulen F: Concordent Materia Medica, ed 3. Haarlem, Emryss Publishers, 2000.

26 Jacobs J, Williams A-L, Girard C, Njike VY, Katz D: Homeopathy for attention deficit/hyperactivity disorder: a pilot randomized controlled trial. J Altern Complement Med 2005;11:799-806.
Biederman J, Lopez FA, Boellner SW, Chandler MC: A randomized, double-blind, placebo-controlled, parallel-group study of SLI381 (Adderall XR) in children with attention deficit/hyperactivity disorder. Pediatrics 2002;110:258-266.
8 Graham J, Banaschewski T, Buitelaar J, Coghill D, Danckaerts M, Dittmann RW, Döpfner M, Hamilton R, Hollis C, Holtmann M, Hulpke-Wette M, Lecendreux M, Rosenthal E, Rothenberger A, Santosh P, Sergeant J, Simonoff E, Sonuga-Barke E, Wong IC, Zuddas A, Steinhausen HC, Taylor E; European Guidelines Group: European guidelines on managing adverse effects of medication for ADHD. Eur Child Adolesc Psychiatry 2011;20:17-37. 